reduce considerably the impact of pulse pressure waves under normal circumstances and may contribute towards protecting this vessel from the disturbances resulting from atheroma. The occurrence of symptoms related to the right artery in patients on oral contraceptives underlines the fact that influences other than simple disease of the arterial wall must be responsible.

We have always considered such occlusions to be embolic in origin when they affect the cerebral vasculature, ${ }^{7}$ and Enzell and Lindernalm ${ }^{8}$ have made one suggestion which might overcome the problem of how any embolism, other than one from the heart or great vessels in the neck, could reach the arterial side of the cerebrovascular system without a septal defect in the heart and a right-left shunt. They produced strong arteriographic support for the theory of embolism and suggested that the pulmonary vascular bed might be a source. They could not prove this, but clearly it is a possibility that needs careful study in future necropsy material.

We ourselves have no explanation to offer for the right-sided predominance in the cases studied, and record the fact mainly to draw attention to yet another tantalising facet of the enigma of cerebral arterial occlusion occurring in women using contraceptives.

\section{References}

${ }^{1}$ Hutchinson, E C, and Yates, P O, Brain, 1956, 79, 319.

${ }^{2}$ Hutchinson, E C, and Yates, P O, Lancet, 1957, 1, 2 .

3 Hulten-Gyllensten, I, Acta Psychiatrica et Neurologica, 1954, 29, 79.

${ }^{4}$ Salmon, M L, Winkelman, J Z, and Guy, A J, Fournal of the American Medical Association, 1968, 206, 85.

5 Bickerstaff, E R, Neurological Complications of Oral Contraceptives. Oxford, Clarendon Press, 1975.

6 Radner, S, Acta Radiologica, 1951, suppl No 87.

7 Bickerstaff, E R, British Medical fournal, 1973, 4, 736.

${ }^{8}$ Enzell, K, and Lindernalm, G, British Medical fournal, 1973, 4, 507.

9 Ask-Upmark, E, Acta Medica Scandinavica, 1966, 179, 463.

10 Ask-Upmark, E, Acta Medica Scandinavica, 1969, 185, 118

11 Odeberg, B, Opuscula Medica, 1967, 8, 338.

12 Hawkes, C H, British Medical fournal, 1974, 4, 379.

${ }^{13}$ Hawkes, C H, personal communication, 1975.

${ }^{14}$ Stewart-Wallace, A M, British Medical fournal, 1964, 2, 1528.

\title{
Congenital malformation associated with intrauterine contraceptive device
}

\author{
HERBERT BARRIE
}

British Medical fournal, 1976, 1, 488-490

\section{Summary}

Two infants with fibular aplasia and related limbreduction defects were born to mothers who were using copper-containing intrauterine contraceptive devices. The possibility of a causal association is consistent with the known hazards of intrauterine devices and cannot be excluded on the available experimental evidence. More information is urgently needed, and searches, including radiography of placenta and pelvis, should be made for such devices in mothers who may have used them in the past and who give birth to malformed infants.

\section{Introduction}

Despite the growing list of complications from intrauterine contraceptive devices, congenital anomalies have not so far been attributed to them. This report describes two infants with unusual limb reduction malformations born to mothers who had been fitted with intrauterine devices.

\section{Case 1}

The first child of a 26-year-old mother was born at term after a normal pregnancy and labour. There was no history of exposure to drugs or $x$-rays during labour, but his mother had been fitted with a coil two years previously, despite which conception had occurred. At birth the baby's condition was good: the Apgar score at one minute was 7 , birth weight $3180 \mathrm{~g}$, length $50 \mathrm{~cm}$, and head circumference $37 \mathrm{~cm}$. An unusual pattern of limb reduction malformation

Paediatric Research Laboratory, Charing Cross Hospital, London W6 8RF

HERBERT BARRIE, MD, FRCP, consultant paediatrician affecting all limbs was immediately evident, however (fig 1). The right arm appeared to end just below the elbow in two rudimentary digits. The left arm was normal as far as the hand, which had a normal thumb but only three fingers, two of which were fused. The feet were held in a valgus position and there were only four toes on each side. The left leg was shorter than the right and there was a longitudinal dimple running down the medial border of the shin, suggesting absence of the fibula. He was normal in all other respects. The placenta was normal and weighed $480 \mathrm{~g}$, while the cord contained the normal three vessels.

A skeletal survey (fig 2) confirmed the absence of the left fibula and the right ulna. The right radius was short and narrow, and there were only two right metacarpals. On the left there were four metacarpals and digits but only one ossified tarsal bone. The skull, ribs, pelvis, and spine were radiologically normal.

A plain radiograph of the mother's pelvis after delivery confirmed the presence of a radio-opaque intrauterine ring, which was subsequently removed and identified as a Grafenberg ring. It was submitted for emission spectrographic analysis and was found to be composed mainly of silver but containing significant impurities of copper $(0.05-0.5 \%)$ and lead $(0.01-1 \%)$. It contained no barium, less than $0.1 \%$ of aluminium and silicone, and under $0.05 \%$ of boron, iron, magnesium, and sodium.

During two years of follow-up this baby's progress has been good and when he was last seen he was developmentally normal for his age, allowing for his motor handicap, although growth has occurred in the affected limbs.

\section{Case 2}

This child was the first baby of a 26 -year-old mother who conceived despite a plastic intrauterine device that had been fitted abroad five months before the start of the pregnancy. To her knowledge the device had never been extruded and she was under the impression that it had stayed in situ throughout the pregnancy. A routine chest $x$-ray picture was taken in the 8 th week and the pregnancy was normal except for a mild untreated influenzal illness in the second trimester. She was delivered at term after a normal labour. The baby weighed about $3600 \mathrm{~g}$ and was normal except for obvious limb reduction malformations. He was brought back to this country at the age of 3 months. On examination the right hand was smaller than the left and bore a normal thumb and three fingers. The right leg and foot 

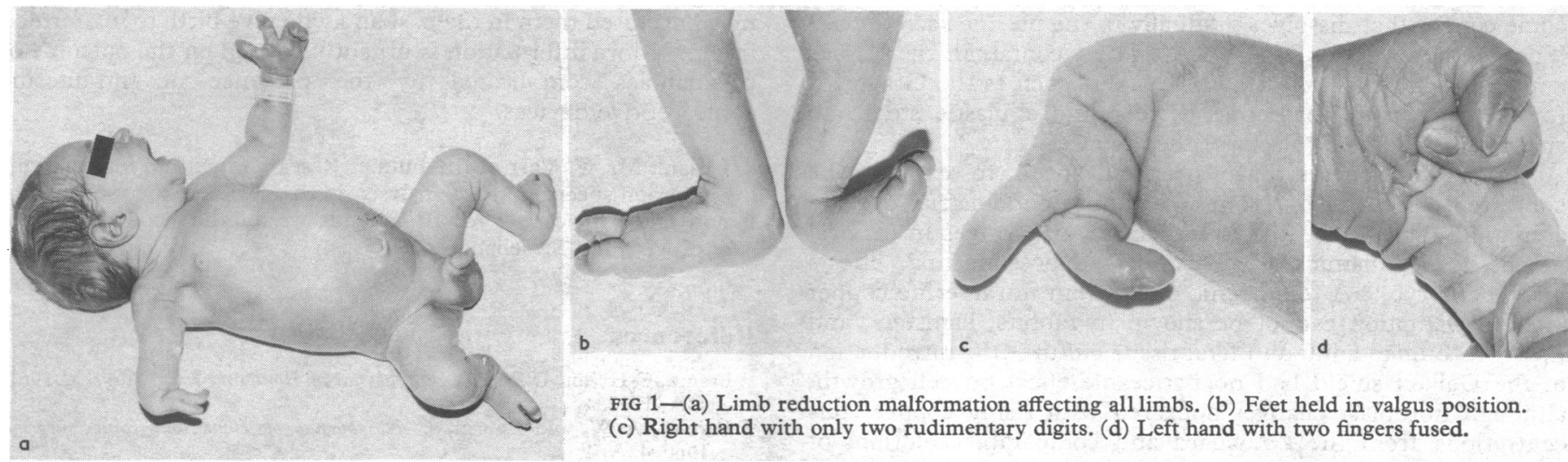

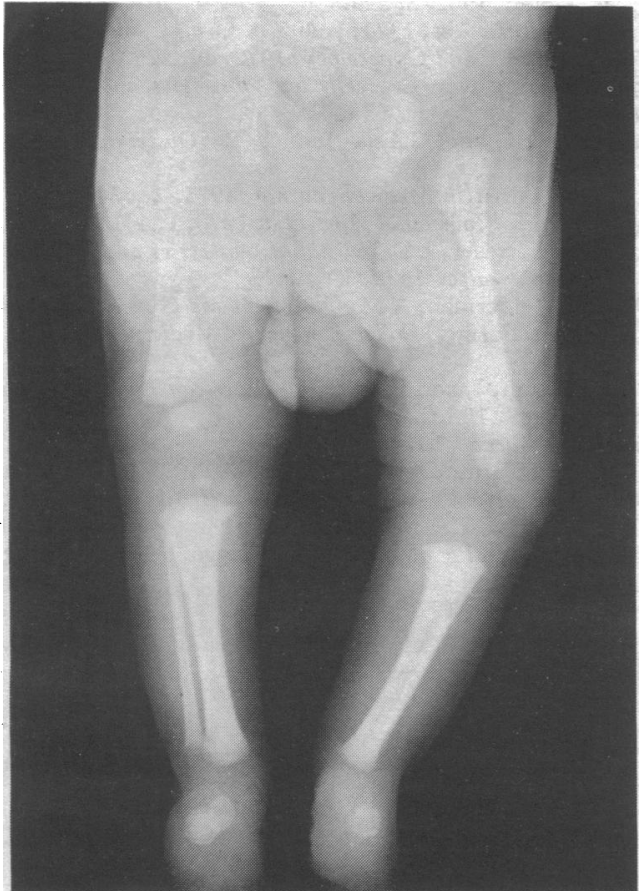

FIG 2-Skeletal radiograph showing absence of left fibula.

were also smaller, the fifth toe was absent, and there was a longitudinal dimple down the medial border of the shin, suggesting absence of the fibula. He was otherwise normal and his level of develment was slightly in advance of his age.

Skeletal survey confirmed absence of the right fibula, one right metacarpal and finger, and the fifth right metatarsal and toe and showed a general degree of underdevelopment of the distal parts of the affected limbs.

A plain radiograph of the mother's pelvis 3 months after delivery failed to show a radio-opaque intrauterine device. She identified the device that had been used as a Dalkon shield from illustrations and samples. This device is partially radio-opaque owing to its barium content, and it may have been expelled at the time of birth or in the puerperium and the evidence of an in situ device during the pregnancy was only circumstantial. A standard Dalkon shield was submitted for spectrographic analysis and was shown to be composed of a vinylacetate polymer containing significant additives of barium $(2 \%)$ and copper $(0 \cdot 2 \%)$.

\section{Discussion}

Apart from those born in 1959-62 with defects due to thalidomide, few babies are born with partial or complete absence of the limbs. The so-called reduction malformations, which include many relatively trivial abnormalities of the fingers or toes, occur in about 1 in 5000 of all births and congenital absence of the fibula features in about one in 10 cases of major limb defects. ${ }^{1}$ The syndrome of fibular aplasia is characterised by a varying degree of shortening below the knee, anterior bowing of the tibia, a skin dimple at its apex, equinovalgus deformity of the foot, and deficiency of the outer tarsal bones. The absent fibula may be replaced by a fibrous band or it may partly ossify later. Other long bones, especially the radius and femur, are also often affected. ${ }^{2}$ The cause is unknown but the condition is not inherited and with the lessons of thalidomide in the recent past environmental causes must be seriously considered. It has been estimated that $2-3 \%$ of all human congenital malformations can be attributed to drugs or chemicals. ${ }^{4}$ Fibular aplasia and other limb defects can be produced in animals by administering various chemicals, notably vitamin antagonists and cytotoxic agents, ${ }^{5}$ in early gestation. The discovery of an intrauterine contraceptive device in one mother who gave birth to a malformed infant and its probable presence in the pregnancy of a second raises important issues. The potential hazards of these devices already include ectopic pregnancy, ${ }^{6}$ uterine perforation, ${ }^{7}$ pelvic and fetal infection, ${ }^{8} 9$ bleeding, miscarriage, rhesus sensitisation, ${ }^{10}$ premature labour, and fetal death. ${ }^{11}$ To this list fetal malformation must now be added.

About 5\% of women using an intrauterine device become pregnant and nearly a third go to term. The current conservative management of those who do not abort spontaneously stems from the belief that most of them will have a normal confinement. This view is not supported by the evidence of the few published series.

Of 82 pregnancies associated with failure of an intrauterine device 4 were extrauterine, 24 were legally terminated, 31 aborted spontaneously (many in the second trimester), 3 went into spontaneous premature labour before 34 weeks, and only 14 ended in normal deliveries; one baby died of prematurity and one congenital abnormality (cleft palate) was recorded.12 In a second smaller series of eight women six pregnancies continued beyond 28 weeks but only two women gave birth to surviving infants. ${ }^{13}$

Unfortunately it is not always known how long the device is retained in each pregnancy and details of fetal morbidity are often lacking. The possibility of an association between fetal defects and the retention of an intrauterine device has almost certainly been under-documented. Several congenital abnormalities must be expected since nearly $5 \%$ of all babies are born with congenital defects ${ }^{14}$ while in spontaneous abortions the incidence is much greater. A causal association between a retained intrauterine device and fetal malformation remains to be proved but is consistent with the known hazards.

The action of intrauterine devices is complicated. Apart from their physical presence, their efficacy is enhanced by the addition of copper. The original Grafenberg ring was made of "German silver," which contains significant impurities of copper and other metals. Most of the modern plastic devices also contain 
some copper that dissolves gradually in the uterine secretions. ${ }^{15}$ The Dalkon shield (Robins) is said to contain little surface copper available for release, while others such as the Gravigard (Searle), consisting of copper wire round a plastic stem, are specifically designed to release the metal.

Various hypotheses have been advanced to explain the contraceptive action of copper, including endometrial enzyme alterations that are hostile to implantation, changes in cervical mucus, local inflammatory reaction, and possible toxic effects on the embryo. ${ }^{16} \mathrm{~A}$ teratogenic effect from intrauterine copper after implantation cannot be shown in rabbits, hamsters, and rats. ${ }^{17}$ In human adult and fetal tissue cultures the introduction of the Dalkon shield had no noticeable effect on cell growth, although fibroblast changes appeared with rising copper concentrations from the Gravigard and comparable solutions of copper chloride. ${ }^{18}$

The extrapolation to man of the results of teratological experiments in animals is fraught with difficulties. ${ }^{19}$ In the field of reproduction species differences are particularly variable. In human fetal development the limb buds appear in the fourth week and by the eighth all structures including all fingers and toes are clearly recognisable. The critical period for teratogenesis is relatively short compared with the susceptible period in the mouse or rat, in which it is about a third of the length of gestation. ${ }^{20}$ Before implantation all surviving cells have the potential of forming a complete embryo. During this phase, which extends to six and a half days in mice, eight days in rats, and 12 to 13 days in man, it is difficult if not impossible to induce malformations.

Despite the reassuring experimental work on rodents and human tissue cultures it is unrealistic on the available evidence to dismiss the possibility of a teratogenic effect from a retained intrauterine device. Serious consideration should be given to terminating early pregnancies with a retained intrauterine device. A careful search, including a placental and pelvic radiograph, should be made for intrauterine devices in women who may have used them in the past and who give birth to malformed infants. More information is urgently needed on the outcome of pregnancies complicated by the presence of intrauterine contraceptive devices.

I thank Mr W Warr of the Fulmer Research institute for performing emission spectrographic analysis on the devices. The first patient is now under the care of $\mathrm{Mr}$ Brian Andrews and the second under the care of Mr John Strachan.

\section{References}

${ }^{1}$ Frantz, C H, and O'Rahilly, R, fournal of Bone and foint Surgery, 1961, 43A, 1202.

2 Farmer, A W, and Laurin, C A, fournal of Bone and foint Surgery, $1960,42 \mathrm{~A}, 1$.

${ }^{3}$ Kruger, L M, and Talbott, R D, fournal of Bone and foint Surgery, 1961, 43A, 625.

4 Wilson, J M, Teratology, 1973, 7, 3.

${ }^{5}$ Miller, J W, Lancet, 1962, 2, 599 .

${ }^{6}$ Vessey, M P, et al, Lancet, 1974, 1, 495.

7 Allen, J R, Obstetrics and Gynecology, 1972, 40, 225.

8 Mishell, D R, and Moyer, D L, Clinical Obstetrics and Gynecology, 1969, $12,179$.

'Misenheimer, H R, and Garcia-Bunuel, R, Obstetrics and Gynecology, $1969,34,368$.

10 McCracken, J S, British Medical fournal, 1975, 2, 684

11 Tischler, E, Medical fournal of Australia, 1970, 1, 441.

${ }^{12}$ Steven, J D, and Fraser, I S, Fournal of Obstetrics and Gynaecology of the British Commonwealth, 1974, 81, 282.

${ }^{13}$ Wiles, P J, and Zeiderman, A M, Obstetrics and Gynecology, 174, 44, 484.

14 Telson, M M, and Forfar, J O, Developmental Medicine and Child Neurology, $1969,11,3$.

${ }^{15}$ Zipper, J A, Tatum, J, and Pastere, L, American fournal of Obstetrics and Gynecology, 1969, 105, 1274.

${ }_{16}$ British Medical fournal, 1974, 2, 181.

${ }_{17}$ Chang, C C, and Tatum, H J, Contraception, 1973, 7, 413.

18 Jones, R W, Gregson, N M, and Elstein, M, British Medical fournal, 1973, 1,520 .

19 Warkany, J, Congenital Malformations, Chicago, p 101. Year Book Medical Publishers, 1971.

20 Brent, R L, Pediatrics, 1974, 53, 821.

\title{
Extrinsic allergic alveolitis in Scottish maltworkers
}

\author{
I W B GRANT, E S BLACKADDER， M GREENBERG， W BLYTH
}

British Medical fournal, 1976, 1, 490-493

\section{Summary}

In a survey of respiratory disease in the Scottish malting industry $5 \cdot 2 \%$ of employees were found to have symptoms of extrinsic allergic alveolitis. In most cases the disease was mild and not associated with any serious respiratory disability. It was significantly less common where modern mechanical methods of malting were used. Mycological and serological studies suggested that

Respiratory Unit, Northern General Hospital, Edinburgh EH5 2DQ

I W B GRANT, MB, FRCP, consultant physician

Health and Safety Executive, Employment Medical Advisory Service

E S BLACKADDER, MFCM, DIH, senior employment medical adviser (Scotland)

M GREENBERG, MB, MRCP, senior employment medical adviser

Department of Botany, University of Edinburgh

W BLYTH, BSC, PHD, lecturer it was usually caused by a type 3 allergic reaction to Aspergillus clavatus.

\section{Introduction}

It has been known since the beginning of the century that there is much chronic respiratory ill health among men employed in the malting industry. ${ }^{1}$ The first indication that this might be due, at least in part, to a specific respiratory disease peculiar to maltworkers came in a report from France published nearly 50 years ago. ${ }^{2}$ Although its authors originally suspected that the pulmonary changes were due to some kind of allergic reaction to Aspergillus fumigatus, they eventually discarded this theory because of the absence of eosinophils in the sputum and concluded that the illness was due to a systemic and toxic effect of aspergillus and mucor. The possibility of an allergic basis for some forms of respiratory disease in maltworkers then seems to have been forgotten until seven years ago, when Riddle et $a l^{3}$ and Channell $e t a l^{4}$ reported four severe cases of extrinsic allergic alveolitis occuring in open-floor maltings and apparently caused by a type 3 allergic reaction to $A$ clavatus. The diagnosis in these four cases was supported by clinical, radiographic, mycological, and serological evidence and by provocation test results. 